\title{
PENGARUH PIJAT BAYI TERHADAP PENINGKATAN BERAT BADAN PADA BAYI
}

\author{
The Effect Of Baby Massage On Increasing Weight In Babies \\ Marni \\ Akademi Keperawatan Giri Satria Husada Wonogiri \\ (marnigsh030@gmail.com)
}

\begin{abstract}
ABSTRAK
Latar Belakang: Pijat bayi sangat bermanfaat dalam mengoptimalkan pertumbuhan dan perkembangan bayi/anak, diantaranya adalah meningkatkan penyerapan makanan sehingga bayi lebih cepat lapar dan bayi akan lebih sering menyusu kepada ibunya, sehingga bisa meningkatkan berat badan pada bayi. Tujuan Penelitian : Penelitian ini bertujuan untuk menganalisis pengaruh pijat bayi terhadap peningkatan berat badan pada bayi.

Metode : Penelitian yang digunakan metode penelitian kuantitatif, menggunakan Quasi eksperiment design dengan rancangan Pretest - Postest design. Populasi dalam penelitian ini adalah bayi usia 2-12 bulan di kelurahan Giripurwo Kecamatan Wonogiri yang berjumlah 30 orang. Sampel dalam penelitian ini adalah bayi yang berusia 2 -12 bulan di kelurahan Giripurwo, sampel dalam penelitian ini adalah total populasi. Analisa data pada penelitian ini dengan analisa univariat dan analisa bivariat. Analisa univariat adalah jenis kelamin, usia bayi. Analisa Bivariat untuk membuktikan pengaruh pijat bayi terhadap peningkatan berat badan bayi sebelum dan sesudah treatment menggunakan Uji Wilcoxon. Pengukuran berat badan responden kelompok intervensi dilakukan sebanyak 2 kali, yaitu pertama pada saat pengambilan data sebelum dilakukan pijat bayi, dan terakhir pada saat setelah sebulan dilakukan pijat bayi.
\end{abstract}

Hasil : nilai $\mathrm{P}$ Value $=0,000(<0,05)$ yang artinya ada perbedaan berat badan sebelum dan setelah dilakukan intervensi pijat.

Simpulan: Ada pengaruh pijat bayi terhadap peningkatan berat badan pada bayi.

Kata Kunci: Bayi, Pijat Bayi, peningkatan berat badan.

\begin{abstract}
Background: Baby massage is very useful in optimizing the growth and development of babies/children, including increasing food absorption so that babies are hungry faster and babies will suckle more often to their mothers so that they can increase body weight in babies.

The Aim : This study aims to analyze the effect of infant massage on increasing body weight in infants.

Method: The research method used is quantitative research methods, using Quasi-experiment design with Pretest design - Postest design. The population in this study were infants aged 2-12 months in the village of Giripurwo, Wonogiri
\end{abstract}


District, which numbered 30 people. The sample in this study was infants aged 2 12 months in the village of Giripurwo, the sample in this study was the total population. Data analysis in this study with univariate analysis and bivariate analysis. Univariate analysis is gender, an age of the baby. Bivariate analysis to prove the effect of infant massage on increasing infant weight before and after treatment using the Wilcoxon Test. Measurements of respondents' weight in the intervention group were carried out 2 times, first when taking data before a baby massage, and finally when after a month a baby massage was carried out.

Results: P-Value $=0,000(<0.05)$ which means there are differences in body weight before and after the intervention.

Conclusion: there is the effect of infant massage on increasing body weight in infants.

Keywords: Babies, Baby Massage, weight gain.

\section{PENDAHULUAN}

Lima tahun pertama adalah masa keemasan bagi bayi / anak. Masa bayi adalah masa keemasan sekaligus masa kritis perkembangan seseorang (Departemen Kesehatan, 2009). Dikatakan masa kritis karena pada masa ini bayi sangat peka terhadap lingkungan dan dikatakan masa keemasan karena masa bayi berlangsung sangat singkat dan tidak dapat diulang kembali. Masa tersebut terjadi pertumbuhan dan perkembangan yang optimal, termasuk tingkat kecerdasan anak. Untuk mencapai proses tumbuh kembang yang optimal dipengaruhi oleh beberapa faktor, diantaranya faktor internal dan faktor eksternal. Faktor Internal antara lain usia, jenis kelamin dan keturunan. Dan faktor eksternal misalnya lingkungan, status sosial ekonomi, dan nutrisi. Lingkungan merupakan faktor yang penting karena dengan lingkungan yang baik, bisa mendukung pertumbuhan dan perkembangan anak. Lingkungan yang nyaman, bisa diterapkan oleh orang tua yang mempunyai anak balita, dengan cara melakukan pijat bayi.

Pijat bayi atau sering disebut stimulus touch, merupakan sentuhan komunikasi yang nyaman antara ibu dan bayi. Pijat merupakan terapi sentuhan yang sudah lama dikenal orang, namun masih jarang diterapkan oleh orang tua yang mempunyai anak balita. Pijat bayi merupakan pengungkapan rasa kasih sayang antara orang tua dengan anak lewat sentuhan pada kulit yang berdampak sangat luar biasa (Maharani dan Sabrina, 2009). Sentuhan merupakan ekspresi dari kasih sayang orang tua terhadap anaknya. Dengan sentuhan tersebut, orang tua dan anak akan sama - sama merasa nyaman, karena hubungan kedekatan secara emosional.

Pijat bayi sangat bermanfaat dalam mengoptimalkan pertumbuhan dan perkembangan anak, diantaranya adalah meningkatkan penyerapan makanan sehingga bayi lebih cepat lapar dan bayi akan lebih sering menyusu kepada ibunya, sehingga bisa meningkatkan berat badan pada bayi. Selain itu bayi yang rutin dilakukan pemijatan juga akan terjadi peningkatan kualitas tidurnya, yaitu bayi tidur lebih lelap dan meningkatkan kesiagaan, akibat dari adanya pengubahan gelombang otak. Bayi juga akan lebih kuat sistem kekebalan tubuhnya, sehingga 
akan meminimalkan terjadinya sakit. Penelitian terkait manfaat pijat bayi adalah bahwa pijat bayi bisa meningkatkan berat badan dan pertumbuhan, meningkatkan daya tahan tubuh dan membuat bayi tidur lelap (Cahyaningrum dan Sulistyorini, 2014).

Banyaknya manfaat yang dihasilkan oleh sentuhan tersebut, maka saat ini banyak dilakukan penelitian tentang pijat bayi, karena ternyata manfaat dari pijat bayi tersebut sangatlah besar, baik perkembangan secara fisik maupun secara emosional.

Pertumbuhan dan perkembangan bayi bisa dilihat dengan pengukuran antropometri, khususnya pengukuran berat badan. Berat badan bisa digunakan untuk mendiagnosis bayi baru lahir normal atau BBLR. Bayi dengan berat badan lahir rendah apabila berat bayi lahir $<2500$ gram. Pada masa bayi dan balita, untuk melihat pertumbuhan fisik maupun status gizi bayi yaitu dengan melihat kenaikan berat badan tiap waktu.

Dari hasil wawancara pendahuluan dengan beberapa ibu yang mempunyai bayi, sebagian besar ibu mengatakan jarang memijat bayinya, pijat bayi dilakukan hanya sekali-kali kalau anak kurang enak badan, itupun yang melakukan pijat adalah dukun bayi. Ibu bayi mengatakan berat badan bayinya sedikit sekali peningkatannya. Berdasarkan uraian diatas maka penulis tertarik untuk mengetahui "apakah ada pengaruh pijat bayi terhadap peningkatan berat badan pada bayi".

\section{METODE PENELITIAN}

Penelitian ini menggunakan Quasi eksperiment design dengan rancangan Pretest - Postest design. Populasi dalam penelitian ini adalah bayi usia 2-12 bulan di kelurahan Giripurwo Kecamatan Wonogiri yang berjumlah 30 orang. Teknik pengambilan sampel dalam penelitian ini adalah non probability sampling yaitu total sampling (Rahmi dan Wahyu, 2012). Variabel bebas dalam penelitian ini adalah pijat bayi, dan variabel terikatnya adalah peningkatan berat badan bayi. Instrumen Penelitian yang digunakan dalam penelitian ini adalah lembar identitas responden, lembar observasi (kuesioner peningkatan berat badan).

Data dianalisa dengan analisa univariat dan analisa bivariat. Analisa univariat adalah jenis kelamin bayi, usia bayi. Penyajian masing-masing variabel menggunakan tabel dan diinterpretasikan berdasarkan hasil yang diperoleh.

Analisa Bivariat untuk membuktikan pengaruh pijat bayi terhadap peningkatan berat badan bayi sebelum dan sesudah treatment menggunakan Uji Wilcoxon. Pengukuran berat badan responden kelompok intervensi dilakukan sebanyak 2 kali, yaitu pertama pada saat pengambilan data sebelum dilakukan pijat bayi, dan terakhir pada saat setelah sebulan dilakukan pijat bayi. Lokasi penelitian dilakukan di Kelurahan Giripurwo. Waktu penelitian pada bulan Maret - Juni 2015. 


\section{HASIL DAN PEMBAHASAN}

Penelitian ini dilakukan Kelurahan Giripurwo, Kecamatan Wonogiri, Kabupaten Wonogiri. Di Kelurahan Giripurwo terdiri dari 6 lingkungan yaitu Lingkungan Salak, Lingkungan Kajen, Lingkungan Sanggrahan, Lingkungan Gerdu, Lingkungan Kerdu Kepik dan Lingkungan Kedungringin. Penelitian ini dilaksanakan di Posyandu Melati V di Lingkungan Gerdu, pelayanan posyandu dilakukan setiap tanggal 14, sekali setiap bulan dan Posyandu Melati Makarti VII di Lingkungan Kerdu Kepik dilakukan setiap tanggal 9 setiap bulan. Penelitian ini dilakukan pada bulan April sampai dengan Juni 2015.

Tabel 1. Karakteristik Bayi berdasarkan jenis kelamin

\begin{tabular}{crc}
\hline Jenis Kelamin & Frekuensi (N) & Persentase (\%) \\
\hline Perempuan & 16 & 53,33 \\
Laki-laki & 14 & 46,67 \\
TOTAL & 30 & 100 \\
\hline
\end{tabular}

Berdasarkan Tabel 1 dapat dilihat bahwa mayoritas bayi berjenis kelamin perempuan yaitu 53,33\%, sedangkan yang berjenis laki-laki berjumlah 14 orang $(46,67 \%$.

Tabel 2. Karakteristik Bayi berdasarkan Usia bayi

\begin{tabular}{ccc}
\hline Usia Bayi & Frekuensi $(\mathrm{N})$ & Persentase $(\%)$ \\
\hline $0-3$ bulan & 3 & 10,00 \\
$3,1-6$ bulan & 16 & 53,33 \\
$6,1-9$ bulan & 8 & 26,67 \\
$9,1-12$ bulan & 3 & 10,00 \\
TOTAL & 30 & 100 \\
\hline
\end{tabular}

Berdasarkan Tabel 2 dapat dilihat bahwa mayoritas bayi berusia 3,1 - 6 bulan sebesar 53,33\%.

Tabel 3. Perbedaan Berat Badan Bayi sebelum dan setelah dilakukan pijat bayi

\begin{tabular}{cccccc}
\hline $\begin{array}{c}\text { Kelompok } \\
\text { perlakuan }\end{array}$ & $\begin{array}{c}\text { Nilai } \\
\text { Minimum }\end{array}$ & $\begin{array}{c}\text { Nilai } \\
\text { Maksimum }\end{array}$ & Mean & $\begin{array}{c}\text { Standar } \\
\text { Deviasi }\end{array}$ & $\begin{array}{c}\text { Kenaikan Rata } \\
\text { Rata berat } \\
\text { badan dalam } \\
\text { sebulan }\end{array}$ \\
\hline $\begin{array}{c}\text { Sebelum } \\
\text { Sesudah }\end{array}$ & 4660 & 8550 & 6728,33 & 1177,55 & $\begin{array}{c}876,67 \text { gram / } \\
\text { bulan }\end{array}$ \\
\hline
\end{tabular}


Jurnal Kebidanan Indonesia. Vol 10 No 1. Januari 2019 (12 - 18)

Tabel 4. Analisis Bivariat Uji Wilcoxon peningkatan berat badan pada bayi

\begin{tabular}{ccccc}
\hline Kelompok Variabel & $\mathrm{N}$ & Mean Rank & Sum of Ranks & $\mathrm{P}$ \\
\hline Perlakuan & 30 & 15.50 & 565.00 & 0.000 \\
\hline
\end{tabular}

Karakteristik Responden: Karakteristik bayi berdasarkan jenis kelamin. Pada penelitian ini didapatkan hasil bahwa jenis kelamin responden lebih banyak berjenis kelamin laki-laki yaitu sebesar 53,3\%. Masa pacu tumbuh laki-laki lebih besar daripada perempuan. Pada Usia bayi laki-laki cenderung mempunyai tumbuh kembang yang lebih baik (Widyastuti dan Widyani, 2009).

Karakteristik bayi berdasarkan usia bayi. Pada penelitian ini, didapatkan hasil 53,3 \% berada pada usia 3-6 bulan, Menurut WHO usia 6 bulan pertama kehidupan sangat penting bagi bayi, karena pada usia ini bayi sangat memerlukan asupan gizi yang tinggi untuk memperoleh tumbuh kembang yang optimal (Tri Sasmi Irval, et. al., 2014).

Peningkatan Berat Badan Bayi sebelum dan setelah pijat. Berdasarkan tabel 3 mean berat badan sebelum dilakukan pemijatan adalah 6728,33 sedangkan mean berat badan setelah dilakukan pemijatan adalah 7605 . Hasil ini menunjukkan terjadinya peningkatan mean berat badan pada responden, hal ini sesuai dengan penelitian yang dilakukan oleh Virgia yang menyatakan bahwa berdasarkan hasil penelitian yang diolah melalui uji Mann Whitney didapatkan P Value sebesar 0,000 lebih kecil dari nilai $\alpha(0,05)$ yang berarti ada pengaruh yang signifikan pijat bayi terhadap perkembangan neonatus (Virgia, 2015).

Bayi yang dilakukan pemijatan rutin akan lebih cepat peningakatan berat badannya, hal ini sesuai dengan penelitian sebelumnya yang telah dilakukan oleh Dewi yang menyatakan bahwa pijat bayi dapat meningkatkan berat badan bayi lebih banyak dibanding tidak dipijat (Dewi, et. al., 2011). Informasi yang didapatkan dari Ibu yang bayinya dilakukan intervensi pijat mengatakan bahwa anaknya sering lapar dan akhirnya frekuensi menyusui lebih sering daripada sebelum dilakukan pijat. Hal ini sesuai dengan teori yang menyatakan bahwa bayi yang sering dilakukan pemijatan akan meningkatkan tonus saraf vagus, yang meningkatkan pengeluaran hormon penyerapan makanan dan peningkatan kadar enzim gastrin dan insulin, sehingga penyerapan makanan akan lebih baik dan maksimal. Itulah yang menyebabkan mengapa bayi yang dilakukan pemijatan secara rutin akan lebih cepat terjadi peningkatan berat badannya dibanding yang tidak dipijat (Sugiharti, 2016). Rata-rata kenaikan berat badan perbulan pada bayi yang dilakukan pijat bayi pada penelitian ini adalah 876,67 gram. Hasil penelitian ini sejalan dengan penelitian yang telah dilakukan oleh Elvira dan Azizah yang menyatakan bahwa kenaikan berat badan bayi yang dilakukan pemijatan yaitu sebesar 800 gram/bulan, dan bayi yang tidak dilakukan pemijatan 233,33 gram/bulan (Elvira dan Azizah, 2017).

Berdasarkan tabel 4 diatas menunjukkan nilai $\mathrm{P}$ Value $=0,000(<0,05)$ yang artinya ada perbedaan berat badan sebelum dan setelah dilakukan intervensi pijat, sehingga bisa disimpulkan bahwa ada pengaruh pijat bayi terhadap peningkatan berat badan pada bayi. Hasil ini sejalan dengan penelitian yang telah dilakukan oleh Irva et al yang menyatakan bahwa terjadi peningkatan 700 gram setelah 
dilakukan pemijatan selama dua minggu dengan $\mathrm{p}$ Value sebesar $0,000(\mathrm{p}<0,05)$ ( Irva, et. al., 2014).

Berdasarkan tabel diatas menunjukkan nilai $\mathrm{P}$ Value $=0,000(<0,05)$ yang artinya ada perbedaan berat badan sebelum dan setelah dilakukan intervensi pijat, sehingga bisa disimpulkan bahwa ada pengaruh pijat bayi terhadap peningkatan berat badan pada bayi. Hasil ini sejalan dengan penelitian yang telah dilakukan oleh Irva et al yang menyatakan bahwa terjadi peningkatan 700 gram setelah dilakukan pemijatan selama dua minggu dengan $\mathrm{p}$ Value sebesar $0,000(\mathrm{p}<0,05)$ ( Irva, et. al., 2014).

\section{SIMPULAN DAN SARAN}

\section{Simpulan}

Berdasarkan rumusan masalah dan hasil penelitian yang telah diuraikan maka dapat diambil kesimpulan bahwa karakteristik responden mayoritas berjenis kelamin laki-laki 53,3\% (16 responden), Usia bayi 3,1 sd 6 bulan 53,3 \% (16 responden). Berdasarkan Uji Wilcoxon berat badan bayi sebelum dan sesudah dilakukan pijat diperoleh $\mathrm{P}$ Value sebesar 0,000 yang bermakna bahwa ada pengaruh pijat bayi terhadap peningkatan berat badan pada bayi.

\section{Saran}

Hasil penelitian ini bisa dijadikan referensi bagi mahasiswa keperawatan dan kebidanan khususnya mata kuliah keperawatan anak dan komunitas, juga bisa dijadikan referensi bagi ibu-ibu kader kesehatan balita atau ibu yang mempunyai bayi, agar melakukan pijat bayi secara rutin dengan teknik yang benar agar meningkatkan berat badan pada bayi dan tumbuh kembang bayi.

\section{DAFTAR PUSTAKA}

Cahyaningrum, Sulistyorini. E. 2014. Hubungan Pijat Bayi Terhadap Kualitas Tidur Bayi Umur 0-3 Bulan Di RB Suko Asih Sukoharjo. Jurnal Kebidanan Indonesi, 5(2)

Departemen Kesehatan. 2009. Pedoman Pelaksanaan Stimulasi, deteksi dan intervensi dini tumbuh kembang anak ditingkat pelayanan kesehatan dasar. Jakarta: Departemen Kesehatan RI

Dewi, N.N., Soetjiningsih \& Prawirohartono, E.P. 2011. Effect of massage stimulation on weight gain in full term infants. Paediatrica Indonesiana 51: 202-206.

Elvira. M., Azizah. S. 2017. Pengaruh Pemberian Pijat Bayi terhadap Kenaikan Berat Badan Bayi Umur 0-6 Bulan di BPS Bunda Bukit Tinggi, Jurnal Pembangunan Nagari 2(1):85-94.

Maharani, Sabrina. 2009. Pijat dan Senam Sehat Untuk bayi. Jogjakarta: Kata Hati Rahmi. Y. Wahyu. W. E. 2012. Pengaruh Pijat Bayi terhadap Kenaikan Berat Badan Bayi Prematur di RSUP Dr M Djamil Padang. Ers Jurnal Keperawatan 8(2) : 129-136. 
Rosi Kurnia Sugiharti. 2016. Pengaruh Frekuensi Pijat Bayi Terhadap Pertumbuhan (Berat Badan ) Bayi Usia 1-3 Bulan di Desa Karangsari dan Purbadana. Jurnal Bidan Prada : Jurnal Ilmiah Kebidanan, Vol 7 No 1:4152.

Tri Sasmi Irva, Oswati Hasanah, Rismadefi Woferst. 2014. Pengaruh Terapi Pijat terhadap Peningkatan Berat Badan Bayi, Jurnal Online Mashasiswa (JOM) Bidang Ilmu Keperawatan, Vol. 1 No 2 : 1-9

http://jom.unri.ac.id/index.php/JOMPSIK/article/view/4142 http://jom.unri.ac.id/index.php/JOMPSIK/article/view/4142/4035

Virgia. V. 2015. Pengaruh Pijat Bayi terhadap Perkembangan Neonatus. Jurnal Keperawatan \& Kebidanan, STIKES Dian Husada Mojokerto, Vol 8 dan No 1 : 72-79.

https://jurnalonline.lppmdianhusada.ac.id/index.php/jkk/article/view/44/23

Widyastuti, D \& Widyani, R. 2009. Panduan perkembangan anak 0-1 tahun. Jakarta: Puspa Swara. 